\title{
Sontag, Susan
}

1989 EI SIDA $y$ sus metaforas. Barcelona, Editorial Muchnick, 103 p,p.

Arxiu d'Etnografia de Catalunya, $n^{\circ} 7,1989,266-267$

ISSN: 0212-0372. EISSN: 2014-3885 http://antropologia.urv.cat/revistarxiu

"Pensar acerca de la enfermedadl- Calmar la imaginación del inválido, de manera que al menos no deba, como hasta ahora, sufrir más por pensar en su enfermedad, que por la enfermedad misma eso creo, sería algo! iSeria mucho! (Nietzsche, p.19)

Esta obra, el segunda de los ensayos sobre este tema presentados por la polifacética autora, se refiere a como diversas enfermedades adquieren en momentos historicos especificos significaciones y connotaciones sociales, que hacen que padecerlas sea vivido como particularmente penoso.

Susan Sontag, tiene el especial mérito de habernos presentado dos monografías estupendas sobre el estudio de las enfermedades, Cancer y SIDA en este caso, constituyendo una de las pocas obras de este género escritas por una novelista "no especialista", ni "profesional", sobre temas de salud y enfermedad, manteniendo a lo largo de su trabajo un tono critico, y aportando un tipo de discurso $y$ análisis novedoso.

La obra consta de ocho capítulos intimamente relacionados entre ellos; su separación, es más un recurso literario que esencial.

266 
Pasados diez años de la publicación de Illness as Metaphor", 1978; 1a autora integra en el primer capitulo del libro, la reflexiones, referentes a como en un corto espacio de tiempo, (podría situarse sobre 1983), y en el momento en que se detecta el primer caso de SIDA en EE.UU., se desplazan miedos ancestrales (muerte lenta, deformación, deshumanización) que hasta el momento se habían creído exclusivos del cáncer hacia el SIDA; disminuyendo la carga estigmatizadora del cáncer, a la vez que aumenta progresivamente la del SIDA.

La aparición del SIDA, permite recuperar la primitiva vision de la enfermedad como algo que viene de "fuera" del individuo; es el "otro", el extranjero, el enemigo, el intruso contra el que hay que "luchar". Recuperándose asi una serie de términos, que siendo propios del lenguaje militar, habian sido traspasados con frecuencia a la literatura médica de principios de siglo en relación a las enfermedades infecciosas, $y$ que prevalecen hasta aproximadamente los años cincuenta con la aparición de la penicilina.

Según la autora, la relación de causalidad establecida en el caso del SIDA (contacto con el fluido o la sangre de una persona infectada), es uno de los elementos más determinantes cuando se trata de discernir entre los diversos tipos de metáforas posibles. Pertenecer a un supuesto "grupo de riesgo" es un factor fuertemente estigmatizante, y se hace evidente una identidad que hasta el momento podia permanecer oculta; el SIDA no deja lugar a que nadie se pregunte $\iota p o r$ qué yo?

La dialéctica establecida entre la dimensión social y la cultural de la enfermedad, se hace más evidente en el caso del SIDA; en donde la categoría social de enfermo (HIV positivo) precede a los síntomas de la enfermedad. Se le considera enfermo, mucho antes de sentirse enfermo.

Las causas sociales que hacen que a la epidemia del SIDA se la denomine metaforicamente como la "Peste del siglo $\mathrm{xx}$ ", no es tan solo su aspecto epidémico (la epidemia de gripe de 1918 jamás ha sido considerada una peste); sino porque en ella influyen diversos factores socioculturales y religiosos, que hacen posible evocar el concepto medieval de peste. "Peste", como calamidad colectiva $y$ de fuicio a la sociedad por su laxitud moral (transmisión sexual promiscua).

El SIDA más que el cáncer, pero como la sifilis, parece fomentar lúgubres fantasias acerca de la enfermedad como un proceso capaz de destruir, no $\tan s 610$ al individuo sino también a la sociedad. Según la autora el SIDA es valorado como "un fracaso social".

Susan Sontag se propone con esta obra, no tan s6lo poner en evidencia una serie de metáforas que confunden la realidad y estigmatizan a las personas que padecen diversas enfermedades, sino que además pretende: evidenciarlas, criticarlas y desgastarlas, ya que cree que la sociedad no tiente derecho a defenderse, a costa de $10 s$ enfermos. Finaliza la obra, parafraseando a Lucrecio: "devolvamos la guerra, a los que hacen la guerra". 
pregunta acerca de la capacidad de nuestra sociedad para utilizar los aportaciones cientificas con fines utilitarios.

Haber extraido el óvulo del útero de la mujer y haberlo fecundado con esperma en una probeta de laboratorio, tiene dimensiones que van más allá de una práctica médica orientada a facilitar la reproducción a parejas estériles. El temor está en que la medicina se convierta en predictiva, en ofrecer a los futuros progenitores la posibilidad de elegir "un niño a la carta", en crear el deseo de que 108 futuros niños o niñas sean a imagen y semejanza de alguien, posiblemente a gusto de quien pueda pagar la intervencion cientifica para establecer la carta genética del embrión, un verdadero "carnet de identidad", un inmejororable regalo al deseo narcisista.

La FIVITE no soluciona $10 s$ problemas de todas las parejas estériles con deseos de hijos, hoy por hoy, sólo una minoria de esas parejas ven resueltos sus sueños. Para otras, intentar la FIVITE y fracasar agrava la angustia de esa esterilidad que no se resignan a asumir.

El segundo capitulo es la "matriz" del libro. Con ironia y escepticismo, nos narra su propia experiencia como padre de la primicia transformada en bebé. El lector participa de esa carrera embriagadora donde se busca algo aun no saboreado por el conocimiento humano. Trepar al arbol de la sabiduría es tortuoso cuando 10 s colegas y la administración se convierten en espinas, en falsas ramas que atrapan y exprimen. Al hablar de $s i \mathrm{mismo}$, el autor justifica su experiencia, sugiere interrogantes y demanda a la sociedad que asuma la responsabilidad del conocimiento cientifico como transformador de nuestras vidas y nuestra cultura.

En el tercer capitulo Testart muestra desde dentro de la corporacion cientifica las tinieblas y ambigüedades que orientan la conducta de muchos profesionales de la medicina, de los cuales depende la aplicación de la tecnología reproductiva.

Plantea dudas a la humanidad desde su experiencia como cientifico. Ve una sociedad ambigua y contradictoria. El ámbito donde se trabaja con la ciencia está burocratizado, dinamizado por la competencia entre profesionales y por la ansiedad de prestigio. Ante esta realidad tan compleja, la honestidad de algunos cientificos queda diluida en el proceso de socialización de sus descubrimientos. El biblogo investiga lo que el médico aplica. Son dos esferas que se complementan a pesar de que la distribucion de prestigio no es equitativa. La especialización del conocimiento contribuye al progreso, pero aisla al cientifico y le dificulta una valoracion amplia de gu actividad. Todo ello hace creer a Testart que sin una orientación ética resuelta por toda la sociedad, la práctica cientifica y médica queda liberada al fantasma de lo absurdo, a una dinámica que atrapa y arrastra sín saber cómo ni hacia donde. Y lo peor, sin saber ni porqué ni para qué.

El cuarto capitulo contiene información práctica acerca de todas las posibilidades que rodean la FIVITE, desde las más conocidas como la congelación y donación de embriones, hasta las mas espectaculares relacionadas con la manipulación genética del embrión. El estado de la investigación permite preveer cambios воciales significativos y una nueva orientación en las relaciones humanas, donde la reproducción no necesitará de sexualidad, donde la familia adquirirá formas tan diversas que dará trabajo extra a antropólogos y legisladores. La autoreproducción (clonación) dejará de ser un fantasma $y$ las quimeras dejarán de ser mitos.

La nueva realidad puede adelantarse a nuestra capacidad de asimilarla. El avance de la tecnología y la adaptación social que ella impone, sugiere a Testart un inminente suicidio cultural: "El género humano morira porque nuestro sobreviviente pertenecerá a otra cultura; este suicidio no ha sido decidido; resultan de un consenso en el que todos participan. Porque la única manera de durar es es continuar hacia adelante".

Serrés con su toque final (en el apéndice) ve, reflexiona y sugiere acerca de la experiencia de Testart $y$ del avance de la ciencia. Muestra un futuro que no es bueno ni malo solo diferente. Nos enfrenta a un devenir producto de la boda entre 10 artificial y la naturaleza.

Montserrat Juan Jerez Universitat de Barcelona 